\title{
Influence of the Geometry Alteration of the Landslide Slope on its Stability: A Case Study in the Carnian Alps (Italy)
}

\author{
Lesław Zabuski ${ }^{1 *}$, Giulia Bossi $^{2}$, Gianluca Marcato $^{2}$ \\ ${ }^{1}$ Institute of Hydro-Engineering, Polish Academy of Sciences, Kościerska 7, 80-328 Gdańsk, Poland, \\ ${ }^{*}$ Corresponding author \\ ${ }^{2}$ CNR-IRPI - National Research Council, Institute for Geo-Hydrological Protection, Italy \\ e-mails: lechu@ibwpan.gda.pl; giulia.bossi@irpi.cnr.it; gianluca.marcato@irpi.cnr.it
}

(Received September 27, 2017; revised October 25, 2017)

\begin{abstract}
The paper presents the principles of the slope reprofiling and proves the effectiveness of this stabilization measure. The case study of two adjacent landslides in the National Road 52 "Carnica" in the Tagliamento River valley, the Carnian Alps $\left(46^{\circ} 23^{\prime} 49^{\prime \prime} \mathrm{N}, 12^{\circ} 42^{\prime} 51^{\prime \prime} \mathrm{E}\right)$ are the example allowing for illustration of this approach. The phenomena have been studied for more than a decade, making it possible to carry out a detailed geological and geomorphological reconstruction. That was done on the basis of a large amount of monitoring data collected during that period. Since the landslides are threatening an important road, countermeasure works to ameliorate the stability conditions of the slides need to be designed. The paper focuses on the creation of a numerical model consistent with monitoring data and capable of reconstructing the dynamics of both landslides. Two cross-sections, one for each landslide, were selected for the analysis. The geometry of the slip surface was determined on the basis of control points, such as slip surface readings from inclinometers, and geomorphological evidence for the contour. The FLAC2D code was used to evaluate the current stability of these landslides and to determine the effectiveness of changing the slope geometry by removing material from the upper part of the slope and putting it to the lowest part as reinforcement.
\end{abstract}

Key words: geotechnical modelling, landslide risk, monitoring, numerical calculation

\section{Introduction}

In mountain environment ensuring road practicability for major routes is essential since road blockage may cause road diversions that could significantly elongate itineraries. Unfortunately these roads need also to cope with slope instabilities that affect mountain flanks.

The principal aim of the paper is to analyse the principles of the landslide slope reprofiling and to prove the effectiveness of this relatively simple stabilization measure. The case study of two adjacent landslides in the National Road 52 "Carnica" 
in the Tagliamento River valley, the Carnian Alps $\left(46^{\circ} 23^{\prime} 49^{\prime \prime} \mathrm{N}, 12^{\circ} 42^{\prime} 51^{\prime \prime} \mathrm{E}\right)$ are the example allowing for illustration of this approach (Fig. 1).
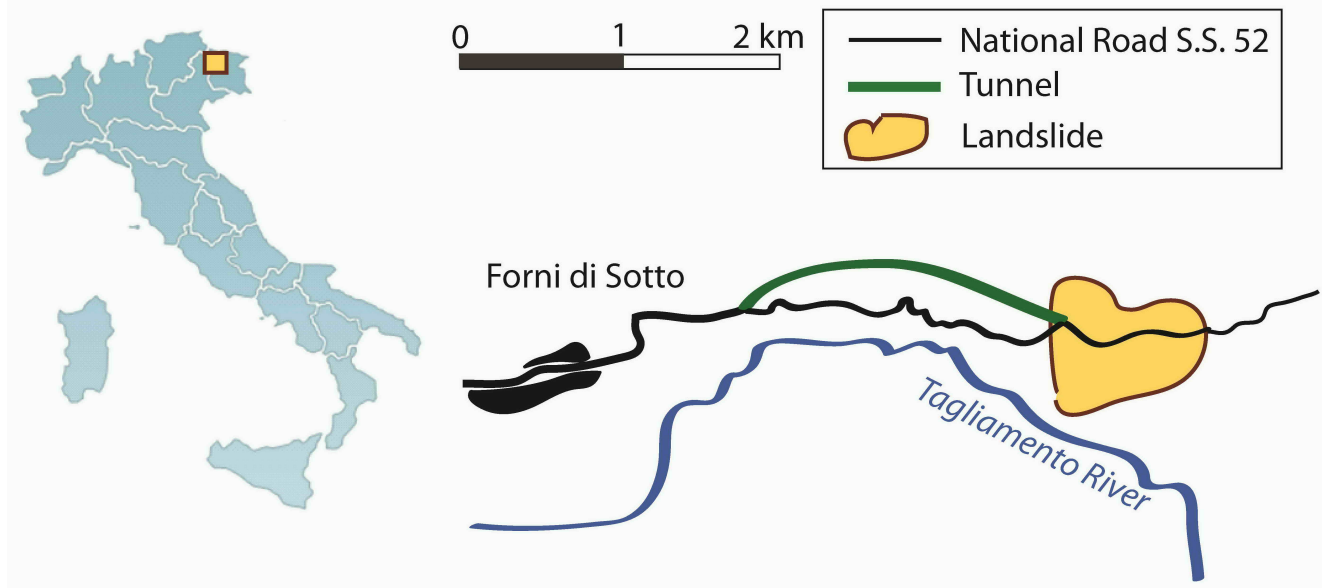

Fig. 1. Location of the analysed slope in the Carnian Alps, N-E of Italy

The stability of two cross-sections of two convergent landslides were analysed with numerical modelling using the FLAC2D code based on the finite difference method. The distribution of the materials within the slope was assigned following the available monitoring evidence. The results of these calculations were then used to design countermeasure works that would guarantee the transit ability of the Passo della Morte road network. These works consisted in removing the material from the most upper zone of the slope and putting it in the region of the slope base. The appropriateness of this action was controlled by means of the numerical calculations.

\section{Study Area}

The road connects the Udine and Belluno provinces, linking the Carnia to the Cadore areas. The landslides examined here are two convergent phenomena divided by a stream called Rio Verde with two distinct crowns that could be classified following the Varnes classification as roto-translational slides (Varnes 1978), (Fig. 2). They develop from an altitude of about 800 to 650 meters a.s.l. with a surface extension of about $1 \mathrm{~km}^{2}$. The average direction of landslide 1 is N-S (Fig. 3) and that of landslide 2, NW-SE (Fig. 4). They can be separated on the basis of monitoring data, and the resulting shape shows a tongue of material rigidly moving in the NW-SE direction and pushed on the western side by another landslide moving from the north to south.

An extensive monitoring system, consisting of piezometers, inclinometers and GNSS benchmarks, provided a large amount of data during the investigation period. On the basis of this information it was possible to characterize the two above mentioned movements (Sinigardi et al 2015). 


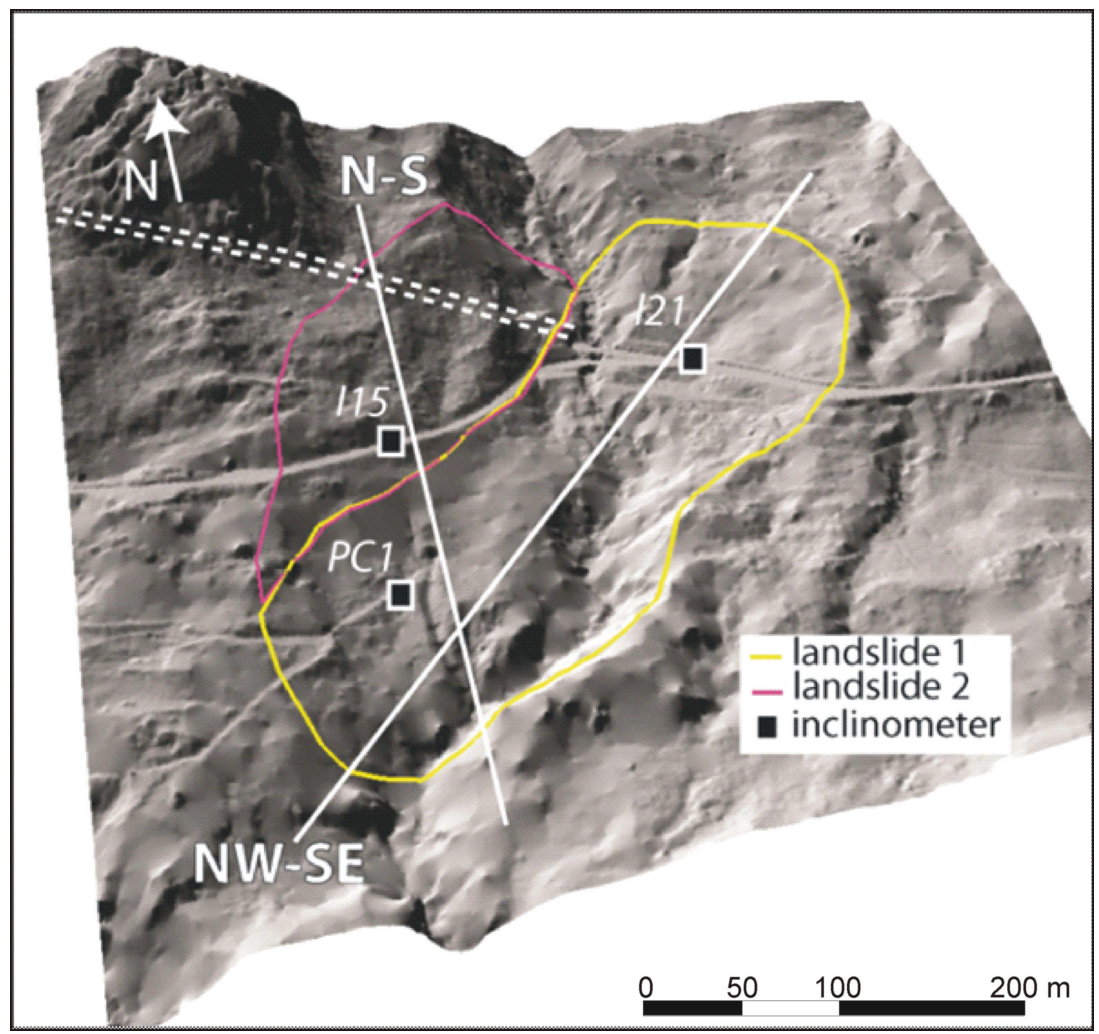

Fig. 2. View of the landslides with two cross-sections analysed numerically

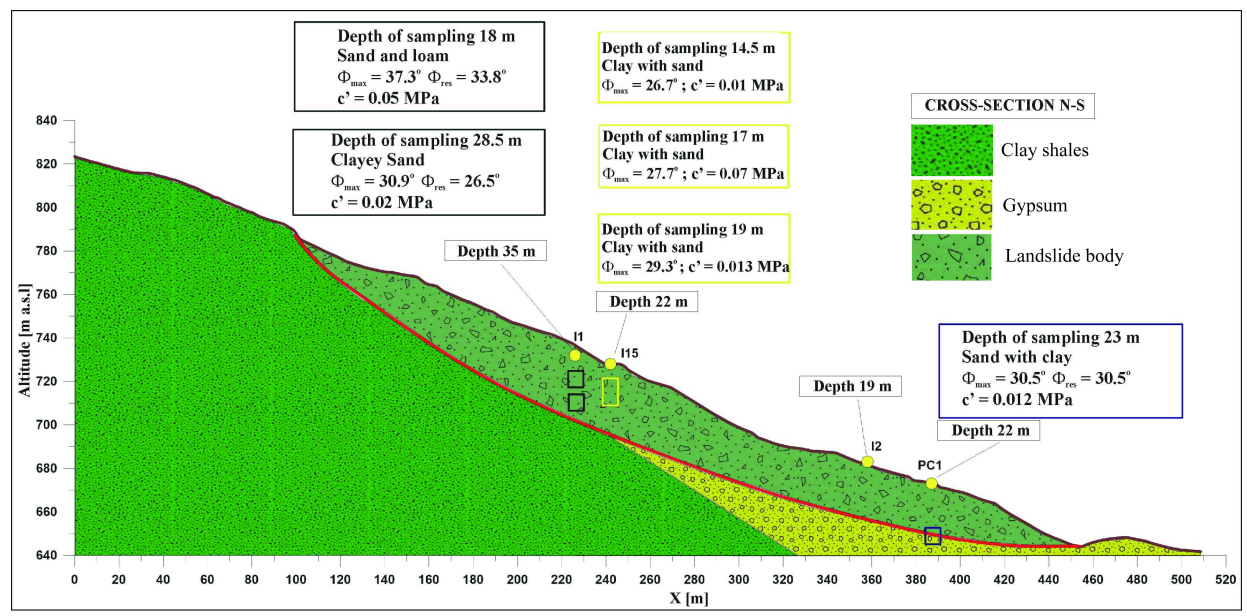

Fig. 3. Geotechnical N-S cross-section with the results of laboratory tests 


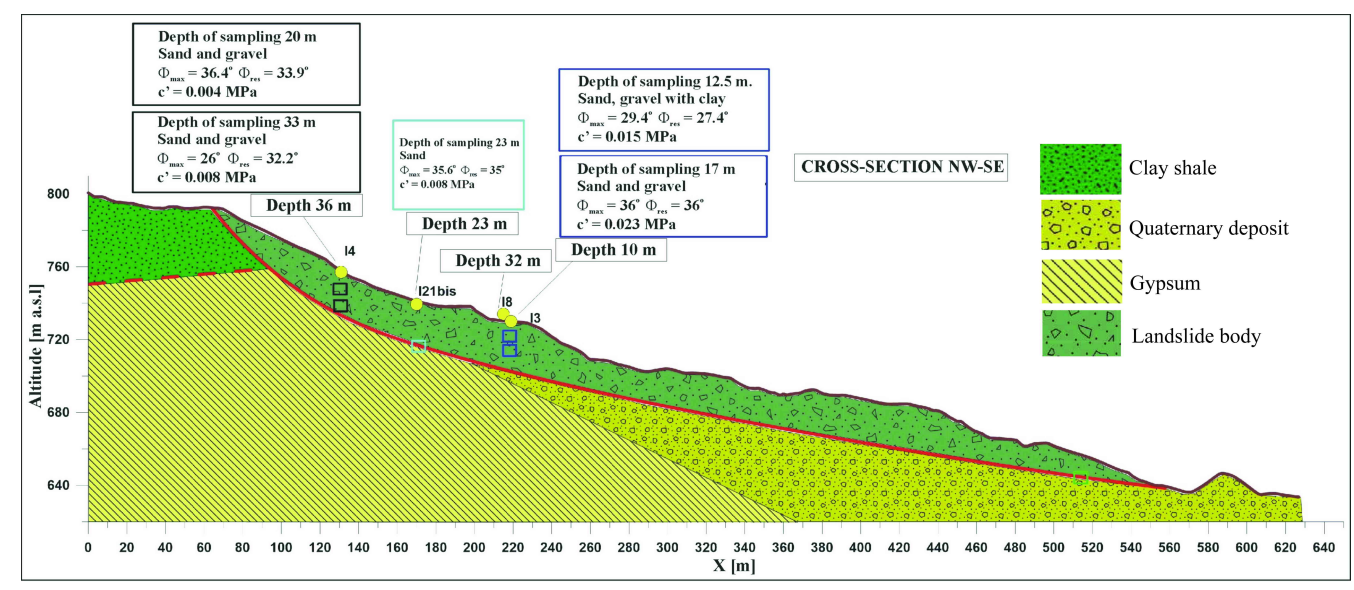

Fig. 4. Geotechnical NW-SE cross-section with the results of laboratory tests

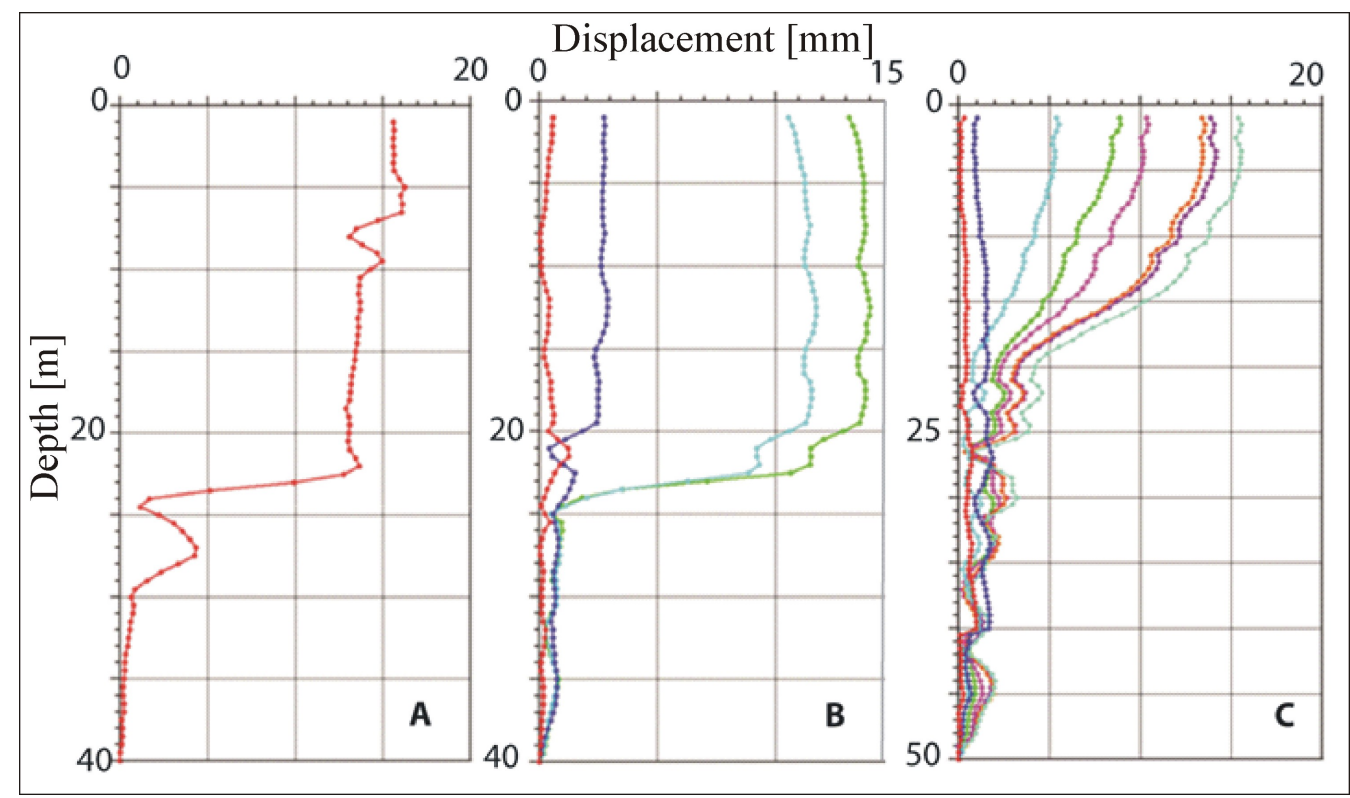

Fig. 5. Inclinometric profiles: A for I21, B for PC1 and C for I15

Inclinometer I21, for example, shows a defined slip surface located $23 \mathrm{~m}$ below the surface for landslide $1(\mathrm{~N}-\mathrm{S})$ with the uppermost part moving as a rigid body (Fig. $5 \mathrm{~A})$. The velocity of the movement, monitored by an in-place inclinometer, is about $5 \mathrm{~cm} /$ year, with peaks of $20 \mathrm{~cm} /$ year after intensive rainfalls. Inclinometer PC1 shows a similar behaviour (Fig. 5A, 5B): translational movement along a distinct slip surface at $23 \mathrm{~m}$ below the surface. Its velocity, recorded by another in-place inclinometer, is again about $5 \mathrm{~cm} /$ year, with peak displacements in sync with $\mathrm{I} 21$. 
On the other hand, inclinometer I15 shows a different, "creeping" displacement pattern. The displacements are distributed along the whole layer of soil above the shear surface, which is less distinct (Fig. 5C).

\section{Numerical Modelling - Original State of the Slope}

A 2D stability analysis was carried out using the FLAC2D computer code (Itasca 2000). The investigated cross-sections, N-S and NW-SE, are indicated in Fig. 2. Some results from geotechnical tests of landslide material were available (see Figs 3 and 4), but for this kind of phenomena it is usually more convenient to determine geotechnical parameters on the basis of a back-analysis procedure in order to match the monitoring data.

\subsection{N-S Cross-section}

The inclinometric curve in the upper part of the landslide body reveals that the entire zone above the bedrock deforms viscously, and a discrete slip surface does not exist (Fig. 6A). In contrast, the inclinometric curve in the lower part proves that the rock mass moves above the narrow slip zone, 2-3 m thick (see Fig. 5) and is only slightly deformed internally (Fig. 6B). These different mechanisms require different modelling approaches. Therefore, the upper part of the slope was considered as a single layer of soil, whereas in the lower part a narrow surface with weaker mechanical properties was inserted (Fig. 7).

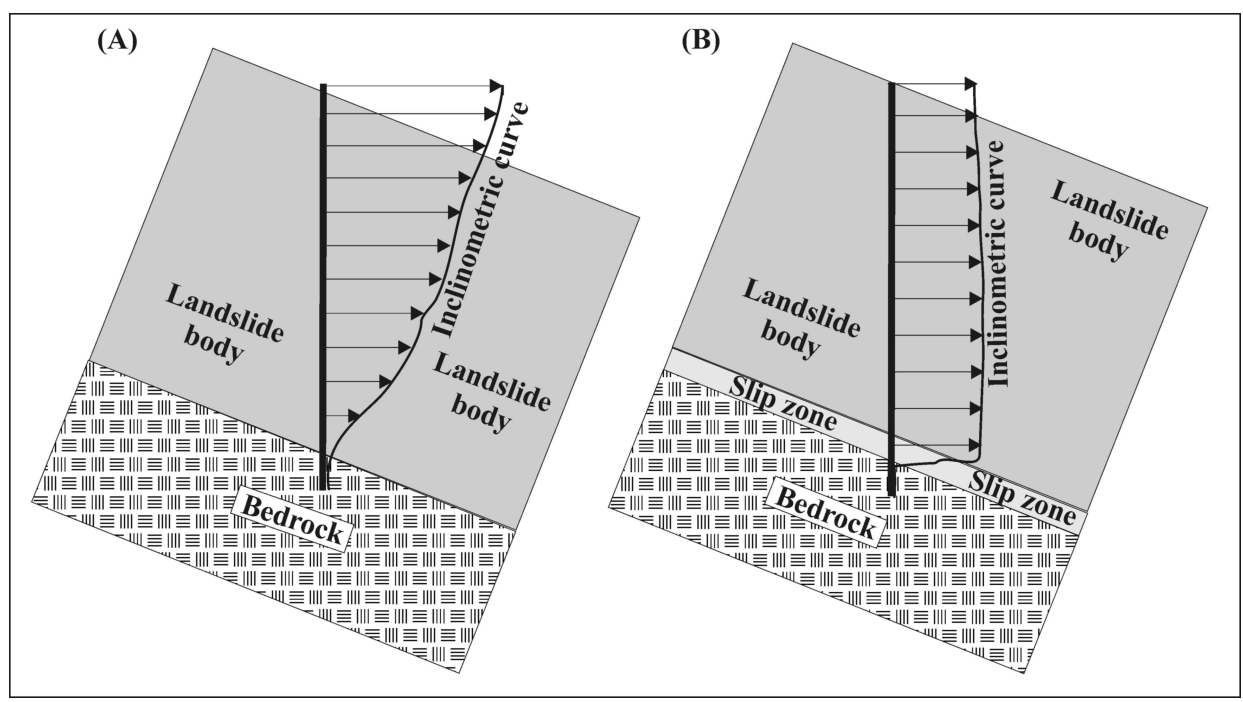

Fig. 6. Schematic inclinometric curves; (A) the whole zone above the bedrock deforms (creep); (B) rock mass above the slip zone moves similarly to rigid, non-deformable material 


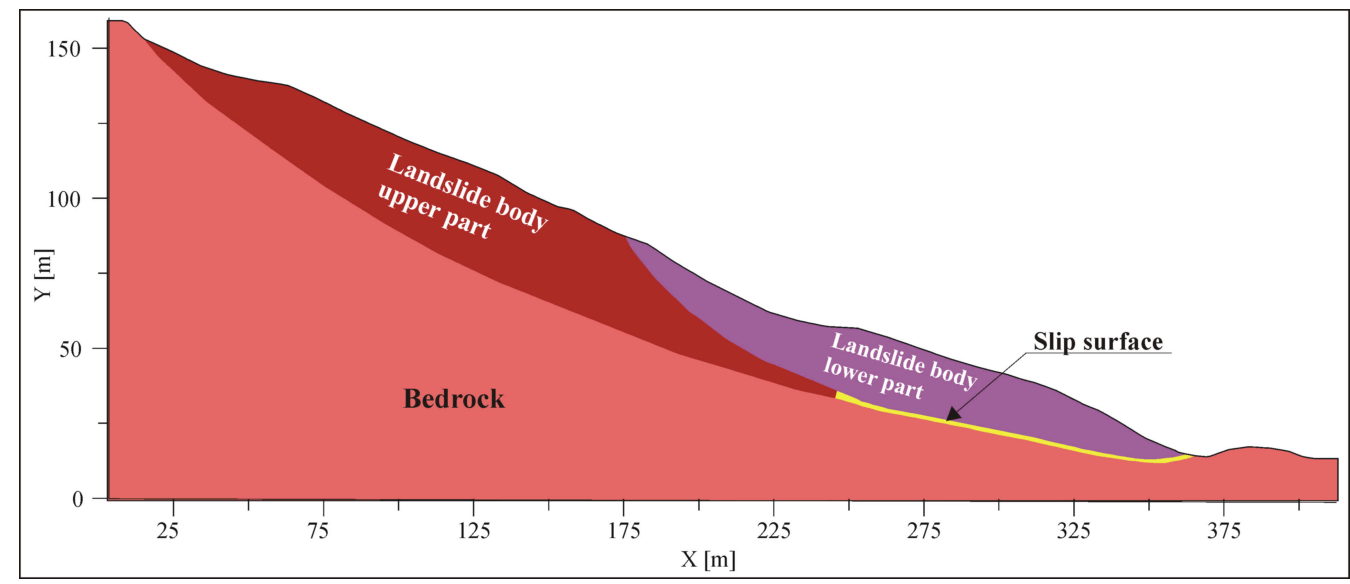

Fig. 7. Division of the model in the N-S cross-section into geotechnical units

The first numerical simulation was performed with the geotechnical parameters of the bedrock obtained in laboratory tests (see Fig. 3). The Coulomb-Mohr criterion was assumed to represent the plasticity limit of the materials. However, the model with these parameters was stable, and that was inconsistent with the actual behaviour of the slope, which is moving. Thus, the parameters of the model (obtained in the laboratory) did not represent well the rock and soil behaviour in the field. To find the state of limit equilibrium with a safety factor of 1.0, i.e. in order to reproduce the state of the slide which is moving but not collapsing, the parameters were gradually decreased. The set of parameters found by this procedure is given in Table 1.

Table 1. Geotechnical parameters for the cross-section N-S

\begin{tabular}{|c|c|c|c|c|}
\hline Unit & $\begin{array}{c}\text { Bulk } \\
\text { modulus } \\
K[\mathrm{kPa}]\end{array}$ & $\begin{array}{c}\text { Shear } \\
\text { modulus } \\
G[\mathrm{GPa}]\end{array}$ & $\begin{array}{c}\text { Cohesion } \\
c[\mathrm{GPa}]\end{array}$ & $\begin{array}{c}\text { Angle of } \\
\text { friction } \\
\Phi[\text { degree] }\end{array}$ \\
\hline Upper part of the slope & 1.67 & 0.77 & 17.86 & 23.66 \\
\hline Slip zone in the lower part & 0.42 & 0.19 & 4.0 & 14.0 \\
\hline $\begin{array}{c}\text { Lower part of the slope } \\
\text { above the slip zone }\end{array}$ & 1.67 & 0.77 & 10.71 & 27.23 \\
\hline Bedrock & 4.17 & 1.92 & \multicolumn{3}{|c|}{ Elastic model } \\
\hline
\end{tabular}

In Figure 8, displacement vectors are shown. The state is very close to limit equilibrium, and although displacements are relatively small, even a small decrease in the plasticity parameters causes an extensive failure.

The appropriateness of the model assumptions concerning the division of the slope into the upper part and the lower part with a thin slip zone can be confirmed by comparison of the real displacement curves in both parts, drawn in Fig. 9. 


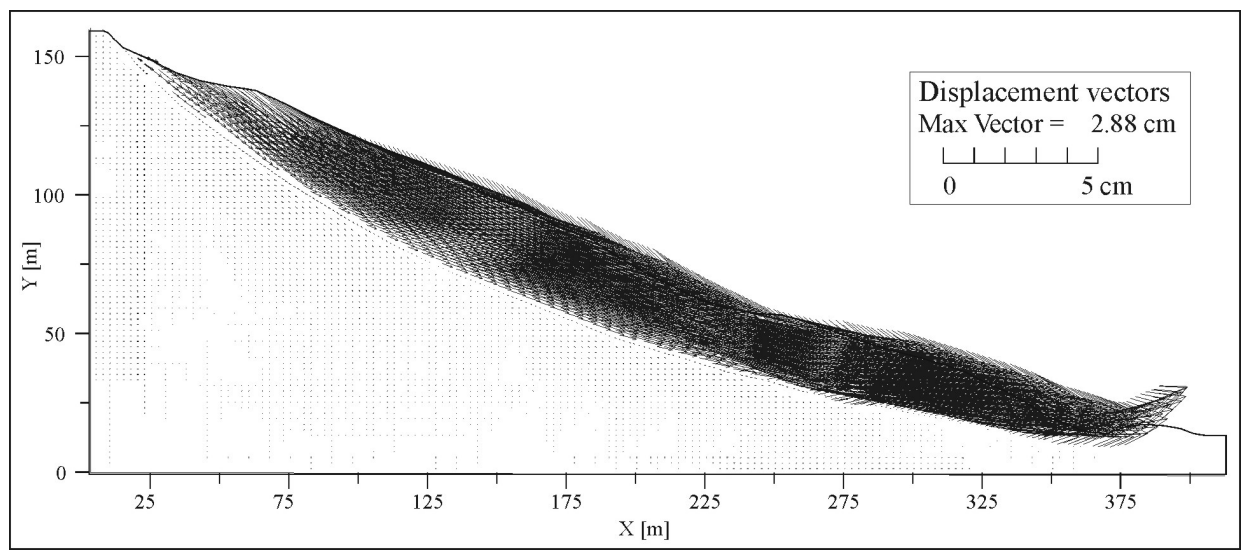

Fig. 8. Displacement vectors of the slope in the N-S cross-section
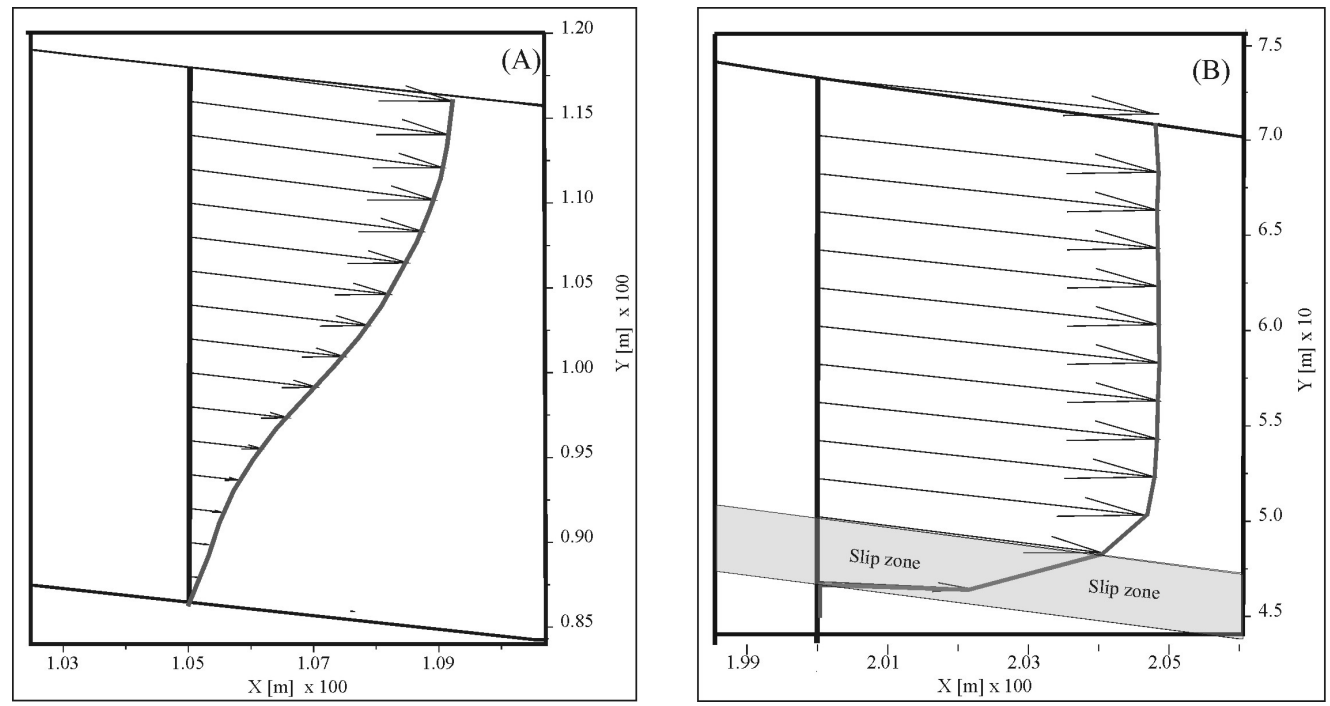

Fig. 9. Shapes of the displacement curves calculated for (A) the upper part of the slope, $X \approx$ $100 \mathrm{~m}$, and (B) the lower part of the slope, $X \approx 300 \mathrm{~m}$

\subsection{NW-SE Cross-section}

The analysis of the NW-SE cross-section followed the same procedure as for N-S. The geomechanical model was divided into three zones, i.e. bedrock, landslide body and a narrow slip zone between them. This zone extends from the main scarp to the toe of the landslide (Fig. 10). The movement mechanism does not change along the whole slip surface, and it was unnecessary to divide this zone in two parts (as was done in the case of the N-S cross-section). The geotechnical parameters are consistent with those determined in the procedure described for the N-S cross-section. The displacement 
pattern recreates accurately the in-situ measurements by inclinometer I21 (see Fig. $5 \mathrm{~A})$.

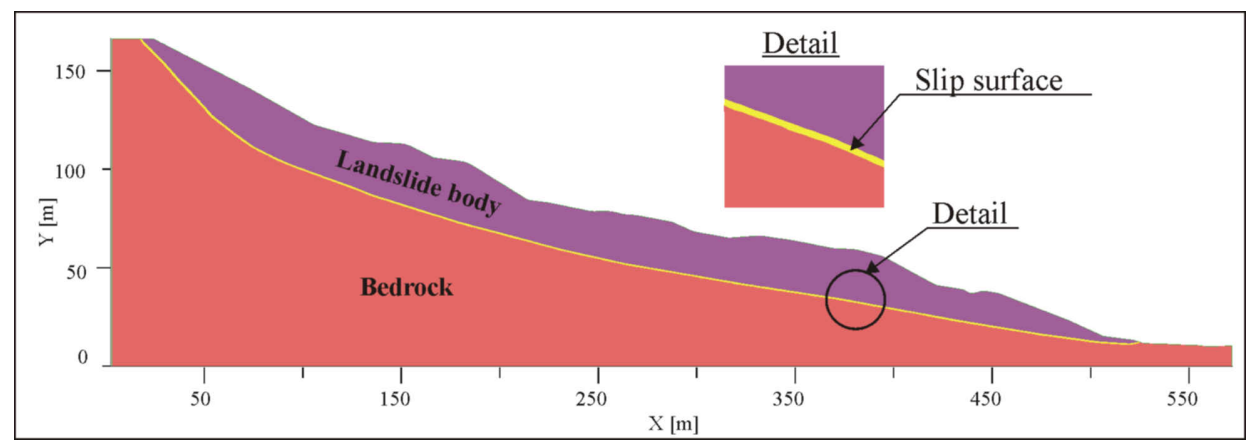

Fig. 10. Division of the model in the NW-SE cross-section into geotechnical units

The slope in the cross-section reaches equilibrium i.e. stabilizes when displacement is equal to about $26 \mathrm{~cm}$ (Fig. 11). Even a very small decrease in the parameters causes an unlimited deformation process.

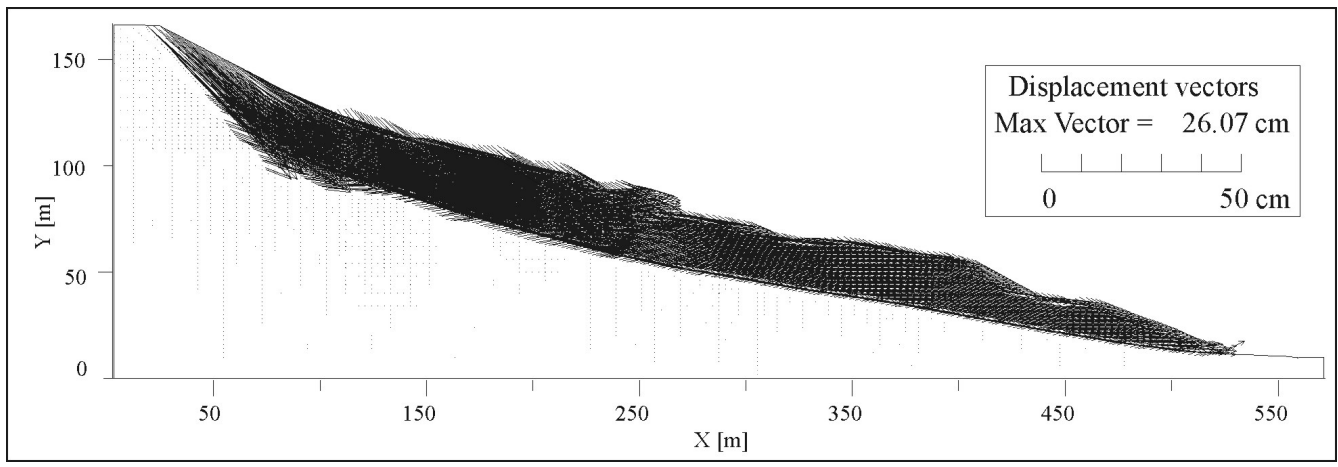

Fig. 11. Displacement vectors of the original slope in the NW-SE cross-section

\section{Numerical Modelling - Altered Shape of the Slope}

A view of the landslides contours with intervention works is shown in Fig. 12. It should be pointed out that the geometry alteration of landslide slopes is one of the basic methods of increasing their stability. Many authors report cases of this approach (Abramson et al 2002, Bromhead 2005, Holtz \& Schuster 1996, Popescu \& Sasahara 2009, Transportation Research Board 2012). Cases have also been reported in which a shape change, e.g. undercutting of the slope, caused accidents (e.g. Jaboyedoff et al 2016).

The main principle of geometry alteration is slope flattening. This can usually be achieved by removing (excavating) material from the upper part of the slope and 


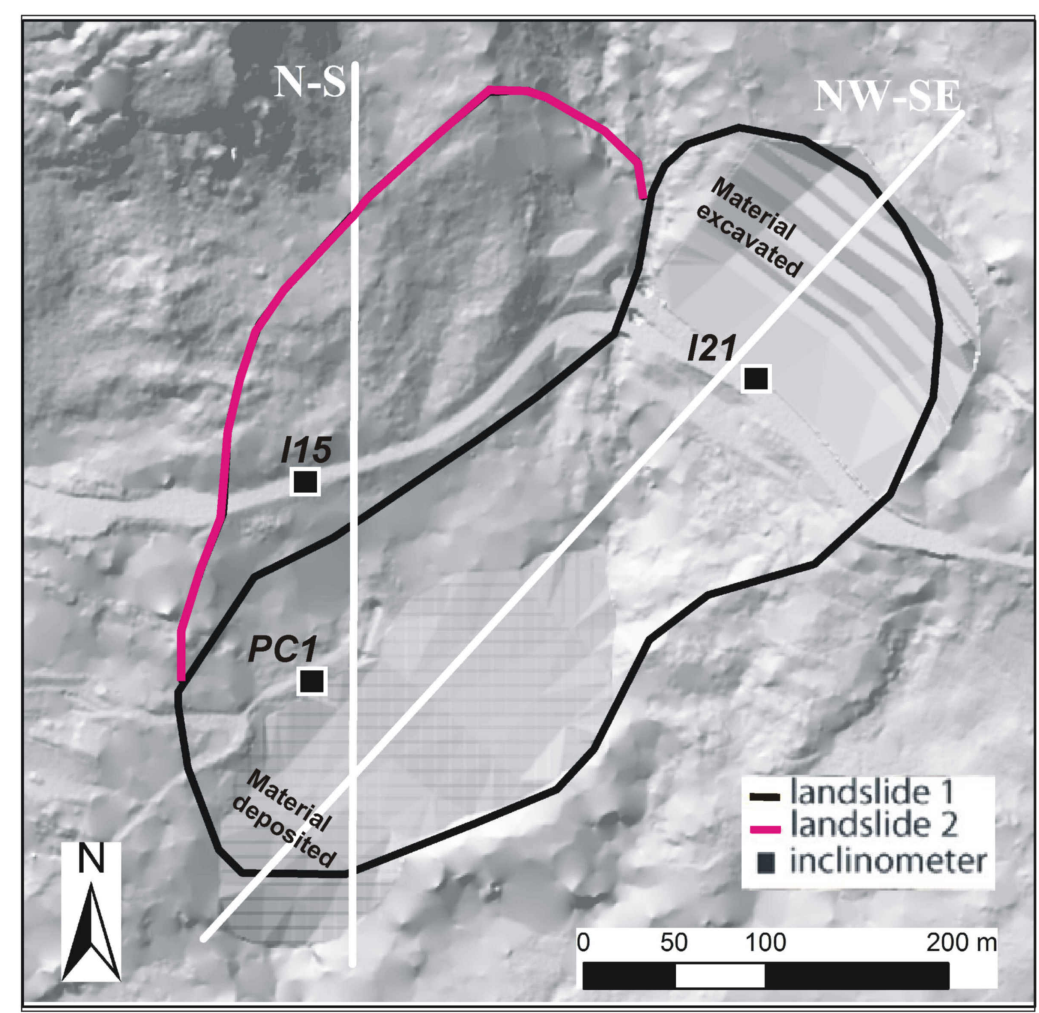

Fig. 12. Landslides contours: results of intervention works are shown (excavation of material from the upper part of the slope and its deposition in the lowest part)

depositing it as support in the lowest slope section. Sometimes only excavation in the upper part or only supporting of the lowest is carried out. In the present case both excavation and deposition of the material are performed.

\subsection{N-S Cross-section}

A simulation was done for the reinforced slope (Fig. 13). The strength parameters of the supporting material are $c=10 \mathrm{kPa}$ and $\Phi=35^{\circ}$. The slope, whose unit parameters are given in Table 1, was stable. These parameters were appropriately decreased to obtain the limit equilibrium state. Equilibrium took place when the parameters (set in Table 2) were lower by 1.17-1.18 than those in Table 1 . In other words, if the reinforcement is carried out, the stability of the slope will be improved, and this improvement is numerically expressed by the safety factor $F=1.17-1.18$.

Figures 14 and 15, in which the displacement vectors and the field of horizontal displacement are presented, respectively, show the situation where, after some displacement, the slope reaches a stable state. However, even a very small decrease in parameter values will cause its failure. 


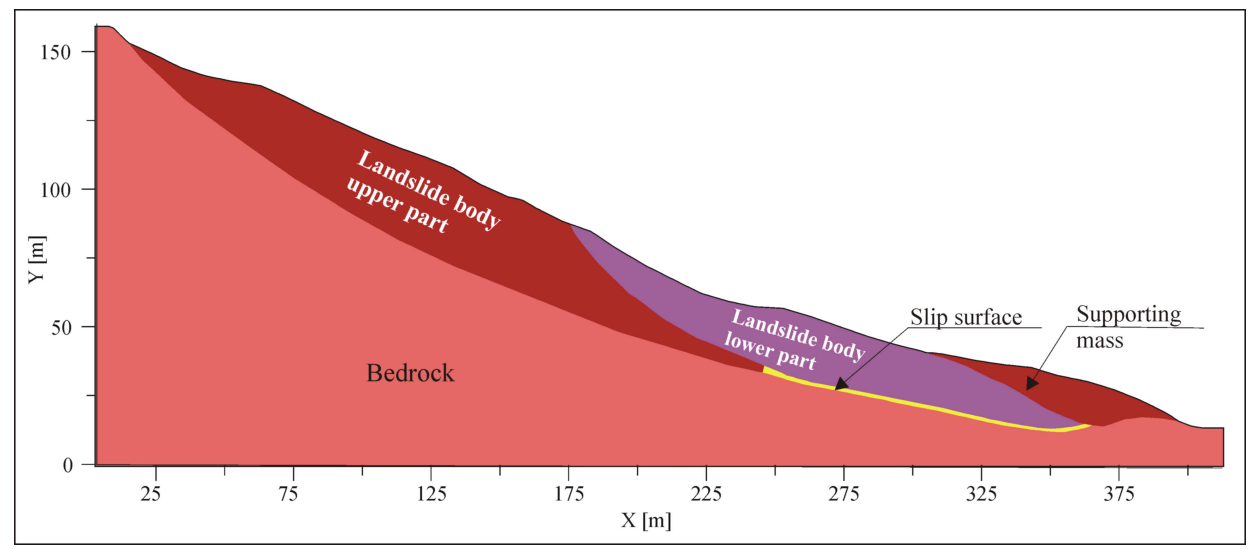

Fig. 13. Division of the model of the supported slope into geotechnical units

Table 2. Geotechnical parameters of the supported slope in the N-S cross-section in the limit equilibrium state

\begin{tabular}{|c|c|c|c|c|}
\hline Unit & $\begin{array}{c}\text { Bulk } \\
\text { modulus } \\
K[\mathrm{kPa}]\end{array}$ & $\begin{array}{c}\text { Shear } \\
\text { modulus } \\
G[\mathrm{GPa}]\end{array}$ & $\begin{array}{c}\text { Cohesion } \\
c[\mathrm{GPa}]\end{array}$ & $\begin{array}{c}\text { Angle of } \\
\text { friction } \\
\Phi[\mathrm{degree}]\end{array}$ \\
\hline Upper part of the slope & 1.67 & 0.77 & $15.13-15.26$ & $20.05-20.22$ \\
\hline Slip zone in the lower part & 0.42 & 0.19 & $3.39-3.42$ & $11.86-11.97$ \\
\hline $\begin{array}{c}\text { Lower part of the slope } \\
\text { above the slip zone }\end{array}$ & 1.67 & 0.77 & $9.08-9.15$ & $23.08-23.27$ \\
\hline Landslide support at the toe & 0.42 & 0.19 & $8.47-8.55$ & $29.66-29.91$ \\
\hline Bedrock & 4.17 & 1.92 & \multicolumn{3}{|c|}{ Elastic model } \\
\hline
\end{tabular}

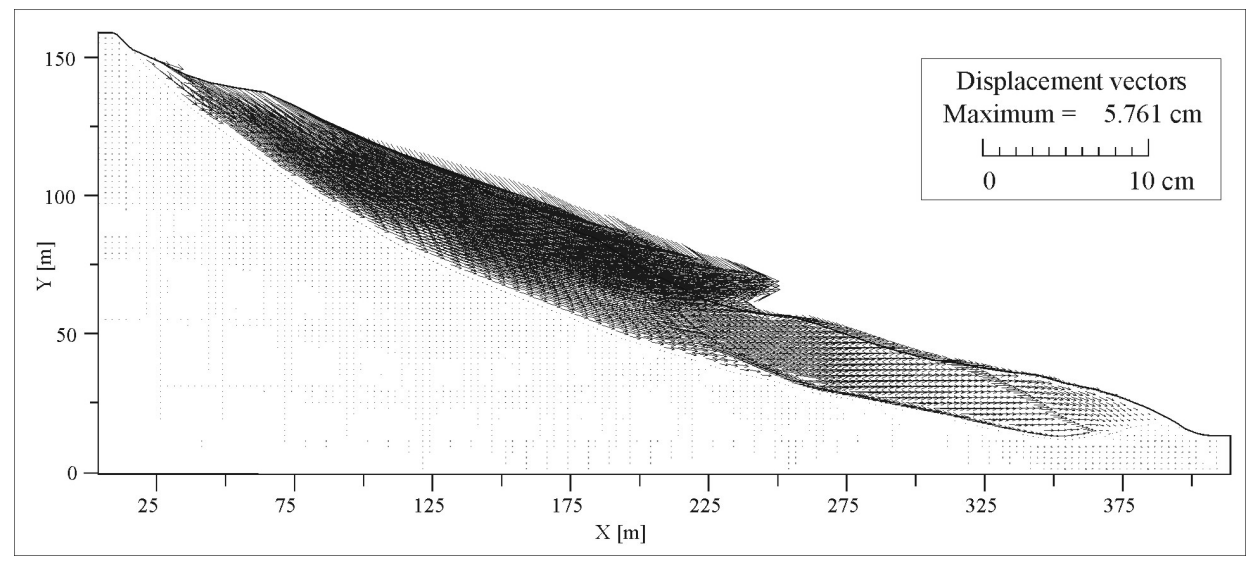

Fig. 14. Displacement vectors of the supported slope in the N-S cross-section 


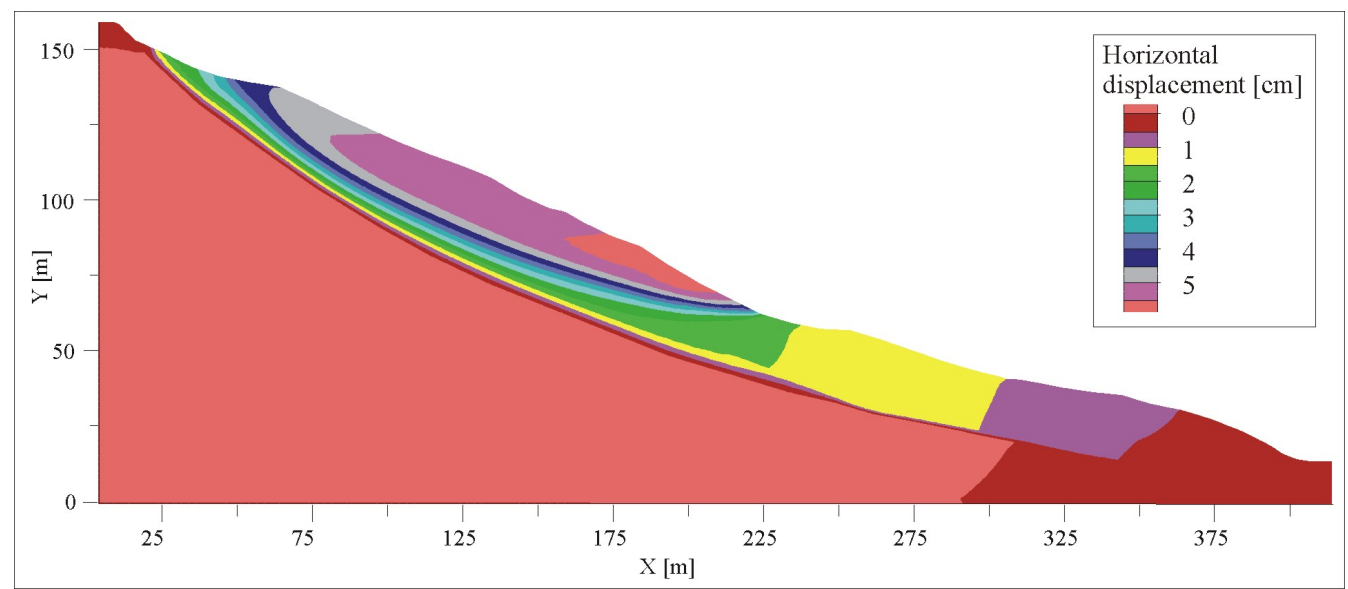

Fig. 15. Horizontal displacement of the supported slope (for $F=1.17$ )

It is concluded that the supported slope is stable, and the safety factor is equal to $F=1.17-1.18$. This increase seems relatively insignificant, but such a small increment is not surprising if one compares the volume of the whole slope with the relatively small volume of the support.

\subsection{NW-SE Cross-section}

In the analysis of the NW-SE cross-section, an identical procedure was used as in the above case. The original NW-SE cross-section was composed of three zones, namely, bedrock, landslide body and a narrow slip zone between them (Fig. 16). The homogeneous character of the slide has been proven by inclinometric measurements, and the creep phenomenon is not observed. The geotechnical parameters of the units are assembled in Table 3. These parameters are consistent with those determined for the $\mathrm{N}-\mathrm{S}$ cross-section.

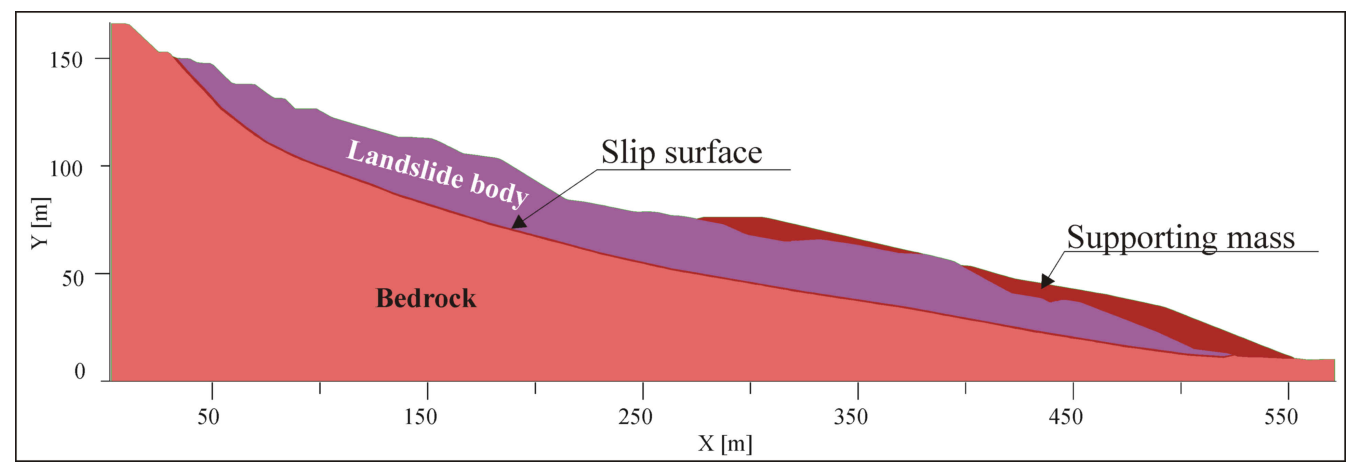

Fig. 16. Division of the model with earth works into geotechnical units 
Table 3. Geotechnical parameters of the slope in the limit equilibrium state

\begin{tabular}{|c|c|c|c|c|}
\hline Unit & $\begin{array}{c}\text { Bulk } \\
\text { modulus } \\
K[\mathrm{kPa}]\end{array}$ & $\begin{array}{c}\text { Shear } \\
\text { modulus } \\
G[\mathrm{GPa}]\end{array}$ & $\begin{array}{c}\text { Cohesion } \\
c[\mathrm{GPa}]\end{array}$ & $\begin{array}{c}\text { Angle of } \\
\text { friction } \\
\Phi[\text { degree }]\end{array}$ \\
\hline Landslide body & 1.67 & 0.77 & 10.71 & 27.23 \\
\hline Slip zone & 0.42 & 0.19 & 5.0 & 15.0 \\
\hline Support & 0.42 & 0.19 & 15.0 & 30.0 \\
\hline Bedrock & 4.17 & 1.92 & \multicolumn{2}{|c|}{ Elastic model } \\
\hline
\end{tabular}

In the case of the NW-SE cross-section, material excavated in the upper part of the slope has also been deposited in the toe region (Figs 16, 17).

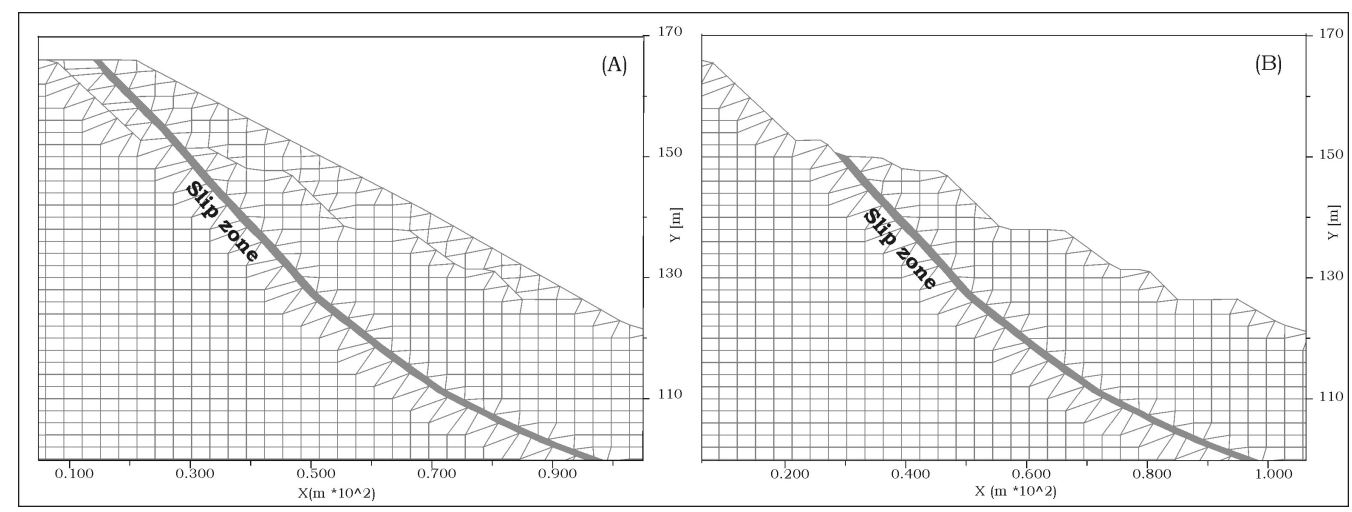

Fig. 17. Shape of material excavated in the upper part of the slope (A) without excavation, (B) with excavation

The next simulation was done for the cross-section altered by the supporting of its lower part and excavation in the upper part. The strength parameters of the reinforcement material are identical as in the N-S cross-section. The slope is stable after a short iteration process, and displacements, concentrated in the upper part, are small.

The parameters in Table 3 were gradually decreased until the limit equilibrium state was reached. Equilibrium took place when they were lower by 1.15 than those in Table 2 (Figs 18, 19). In other words, if the reconstruction in the NW-SE cross-section is carried out by excavation and supporting in the form presented in Fig. 17B the stability of the slope will be improved, and this improvement is expressed by the safety factor $F=1.15$.

It can be concluded that the reinforced slope is stable, and the safety factor $F$ is equal to 1.15 , which is relatively small. As seen in the figures 18 and 19, the supporting of the lower part improves stability conditions in this part, but does not influence the behaviour of the upper part lying in a relatively large distance from the support, and deforms extensively despite the excavation of some of the material. Thus, the relatively small increase in the safety factor results from the behaviour of the upper part of the slope. 


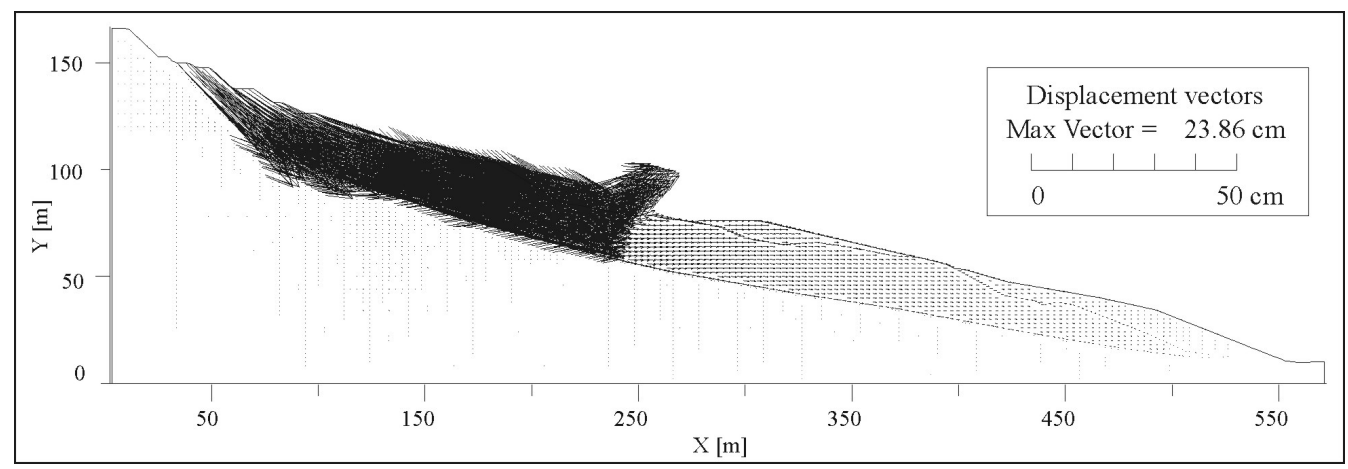

Fig. 18. Displacement vectors of the moving slope in the NW-SE cross-section after execution of the earth works (for $F=1.15$ )

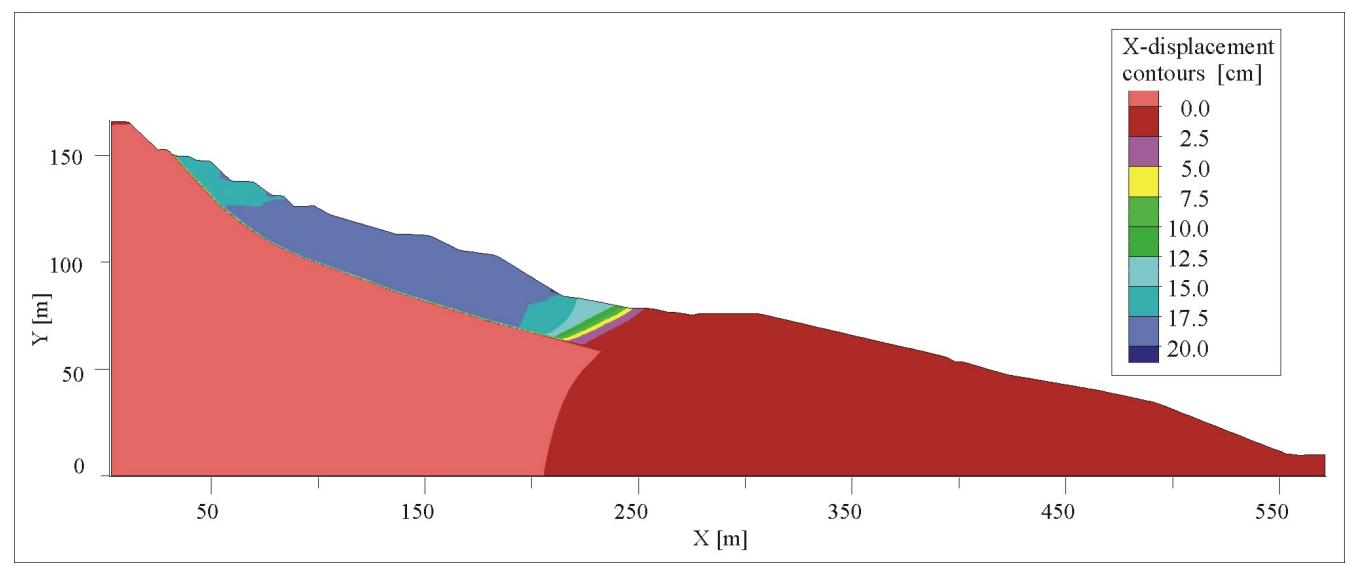

Fig. 19. Horizontal displacement of the slope in the NW-SE cross-section after execution of the earth works (for $F=1.15$ )

\section{Final Remarks}

The behaviour of the landslide slope analysed in two cross-sections shows that remedial works can improve stability conditions. This improvement is not significant, and further deformations, especially in the upper part of the slope, continue. The removal of greater amounts of material from this part and intensive drainage may ameliorate the stability conditions of the slope.

The selected stabilization method is cheaper and more effective than the alternative methods (e.g. retaining walls, anchors etc.), which would be much more expensive. In the case of the analysed slope, it is important to utilize the excavated material as support. All excavated material should be deposited in the lowest part of the slope. The transport of the material to or away from the site would substantially increase the costs of the works. 


\section{References}

Abramson L. W., Lee T. S., Sharma S., Boyce G. M. (2002) Slope Stability and Stabilization Methods, 2nd edition, Wiley \& Sons, New York.

Bromhead E. N. (2005) Geotechnical Structures for Landslide Risk Reduction, [in:] Landslide Hazard and Risk, Glade T., Anderson M. G, Crozier M. J. (eds.), Wiley \& Sons, Chichester, 550-593.

Holtz R. D., Schuster R. L. (1996) Stabilization of Soil Slopes, [in:] Turner A. K., Schuster R. L. Landslides Investigation and Mitigation, National Academy Press, Washington D.C., 437-473.

Itasca C. G. (2000) FLAC 4.0 User's Manual, Minneapolis, USA.

Jaboyedoff M., Michoud C., Derren M. H., Voumard J., Leibundgut G., Sudmeyer-Rieux K., Nadim F., Leroi E. (2016) Human-Induced Landslides: Toward the Analysis of Anthropogenic Changes of the Slope Environment, [in:] Slopes Experience, Theory and Practice, Aversa S., Cascini L., Picarelli L., Scavia C. (eds.), Taylor and Francis Group, Boca Raton, London, New York, Leiden, 217-232.

Popescu M. E., Sasahara K. (2009) Engineering Measures for Landslide Disaster Mitigation, [in:] Landslide Disaster Risk Reduction, Springer, Berlin, Heidelberg, 608-631.

Sinigardi G., Bossi G., Scuri A., Marcato G., Borgatti L. (2015) Geological and numerical models as a tool to manage landslide risk: The Passo della Morte case study (UD, Italy), Rendiconti Online della Societè Geolica Italiana, 34, 46-53.

Transportation Research Board (2012) Cost-Effective and Sustainable Road Slope Stabilization and Erosion Control, NCHRP Synthesis 470, Washington D.C.

Varnes D. J. (1978) Slope Movement Types and Processes, [in:] Special Report 176, Landslides: Analysis and Control, R. L. Schuster, R. J. Krizek (eds.), TRB, National Research Council, Washington D.C., 11-33. 